\title{
Políticas sociales y desarrollo: Una exploración sociológica
}

\author{
Salvador Orlando Alfaro \\ Universidad de Regina \\ Canadá
}

RESUMEN: En las últimas dos décadas, los programas sociales se convirtieron en un mecanismo de control social, por medio de los cuales los actores con mayor poder ejercen una fuerte influencia para legitimar las perspectivas e ideologías en las zonas de pobreza en un marco caracterizado por un modelo de desarrollo inspirado en el neoliberalismo dominante. En este contexto, este trabajo se propone discutir algunos de los temas más relevantes en torno a las políticas sociales en Latinoamérica y mostrar sus efectos en el componente social.

ABSTRACT: In the last two decades, social programs became a mechanism of social control, through which the actors with most power have a strong influence to legitimate their perspectives and ideologies in the poverty zones in a context

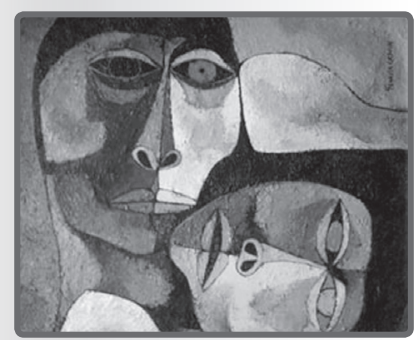
characterized by a development model inspired in the ruling Neo-Liberalism. In this context, this paper discusses some of the most relevant issues regarding social policies in Latin America and its social effects. 
- n las últimas dos décadas,
en América Latina se ha despor los problemas asociados con la "política social", o para ser más precisos por las "políticas de alivio a la pobreza". Este despertar está relacionado con uno de los problemas más visibles que actualmente experimenta la región, la pobreza, cuya superación es apremiante dadas las implicaciones que genera en los diferentes ámbitos de la vida social.

El debate se ha abierto hasta el punto que en la actualidad no sólo se consigue una abundante cantidad de análisis y puntos de vista al respecto, sino que se han creado numerosos escenarios para su discusión, los cuales sirven de sede para la interacción de diversos actores sociales y la construcción y circulación de sistemas de significado compartidos en torno al "alivio a la pobreza", que al legitimarse impactan las dinámicas y prácticas sociales. En el mismo sentido, las diversas representaciones de las políticas sociales expresan una comprensión particular de su vínculo con las ideas del desarrollo y de los modelos a impulsar.

A partir de la década de los ochenta, la mayor parte de los países de la región, ante el quiebre de las representaciones sociales construidas alrededor del desarrollismo, y en una situación de profunda crisis económica, comienzan a

aplicar políticas de ajuste y estabilización económica. Estas políticas se enmarcan en una nueva representación del desarrollo inspirada en el paradigma neoliberal que había expandido su influencia a nivel global, siendo uno de sus principales objetivos llenar el vacío producido por la crisis del paradigma keynesiano y su expresión más relevante: el Estado de Bienestar.

Las políticas de ajuste y estabilización macroeconómica han perseguido la liberalización financiera y comercial de los mercados nacionales y su inserción en una economía globalizada, que responde a las estrategias diseñadas en el centro de la economía-mundo capitalista. Estas recomendaciones de política económicas, resumidas en el llamado "Consenso de Washington", el cual describe las reformas que los gobiernos de América Latina, deberían impulsar un intento de restablecer un manejo económico "racional" en medio de la crisis de endeudamiento, condensan las ideas que acerca del desarrollo manejan los funcionarios del gobierno de los Estados Unidos y de los organismos financieros multilaterales: Fondo Monetario Internacional y Banco Mundial.

El "Consenso de Washington" no hace referencia explícita a la política social. Puesto que de acuerdo al imaginario neoliberal del desarroIlo, el mercado es el código ordenador y asignador de recursos en la sociedad, incluido el bienestar social (Mulvale 2001), y lo que se re- 
fiere a la visión y tratamiento de "lo social" se resume en la frase: "primero crecer, luego distribuir". Sin embargo, a comienzos de la década de los noventa, los costos sociales y políticos de las medidas aplicadas, manifestados en el incremento de la pobreza y la conflictividad social y política, amenazaban la viabilidad del modelo económico. Para dar viabilidad sociopolítica al modelo, algunos actores sociales transnacionales (léase el Banco Mundial) comienzan a incorporar en su concepción de "desarrollo" ideas referidas a las políticas sociales, las cuales orientan algunas acciones sociales destinadas a neutralizar los riesgos políticos del deterioro social y a proporcionar recursos a los sectores poblacionales más impactados negativamente por los programas neoliberales. En este contexto, se construye la idea de "Políticas de alivio a la pobreza"1. Esta nueva representación de la idea de política social es recogida en las estrategias, políticas y programas sociales que se desarrollan en la actualidad.

A fines de los noventa, las limitaciones de las políticas recomendadas para alcanzar tasas de crecimiento sostenidas y para superar los múltiples problemas de la región, como la pobreza, el desempleo, la desigualdad, impulsaron por parte de los organismos multilaterales una revisión de las reformas conocidas como el Post-Consenso de Washington (o reformas de la segunda generación). Dentro de la visión neoliberal del desarrollo, esta nueva generación de reformas amplía las metas del desarrollo, incluyendo aspectos sociales y políticos (Stiglitz 2002). Estas reformas son las que actualmente orientan las políticas de corte social impulsadas en la mayoría de los países latinoamericanos.

En este contexto, el presente artículo se propone discutir algunos de los temas más relevantes en torno a las políticas sociales y mostrar cómo la aplicación de la imaginación sociológica al estudio de esta problemática implica realizar esfuerzos analíticos que posibiliten su comprensión y, principalmente, que permitan señalar cuáles son los efectos concretos que tienen estas intervenciones sobre amplios sectores del componente social de nuestras formaciones.

\section{II}

- n las formas modernas del - Estado de Bienestar, la intervención en materia de políticas sociales ofreció un lugar al ciudadano, pero también obligó al Estado a proveer asistencia y ser el soporte de todo aquel que tuviese necesidades como consecuencia de las transformaciones económicas.

Claus Offe (1984) analizó en su tesis los cambios producidos en las políticas públicas e indicaba que las sociedades europeas, altamente organizadas, homogéneas y estables se estaban desestructurando. Las consecuencias recayeron directamente sobre el denominado Estado de Bienestar, un modelo que fue 
perdiendo apoyo, produciendo un proceso paulatino de desintegración con fuertes repercusiones en distintos sectores ${ }^{2}$.

La causa de la crisis del Estado se centró en el ámbito económico, dejando de lado la importancia que tuvo la intromisión de la política en el mercado en donde el Estado era el que regulaba y asignaba los recursos. Esta perspectiva económica fue utilizada como instrumento capaz de generar estos cambios, dejando de lado el paradigma del "bien común". De esta manera, y según lo señala Offe, la política perdió su base ética produciendo lo que luego se denominó "el costo social del ajuste" (1984: 186).

El plan neoliberal expresa un ambicioso proyecto de transformación de las relaciones entre los principios de organización del sistema de bienestar social que comprenden al Estado, al mercado y la familia (Jessop 2002). Este modelo neoliberal presenta ciertos rasgos resaltantes en las políticas sociales, caracterizado por:

1. Una marcada tendencia hacia la privatización que pone en desventaja la estructura incompetente del Estado.

2. La desigualdad de la condición ciudadana que restringe el concepto de universalidad de los servicios básicos como son la educación, la salud, etc.

3. Intervenciones focalizadas en las necesidades coyunturales y selectivas a pequeños grupos de población.

Las razones son los nuevos escenarios socioeconómicos que han marcado las dos últimas décadas de la política de la mayor parte de países de la región, incluyendo a El Salvador, en donde la ineficacia de estas intervenciones no ha sido capaz de dar respuesta a los problemas acarreados por el pérdida de recursos financieros del sector público. Las transformaciones acaecidas en la última década en materia de políticas públicas fueron traducidas en procesos complejos internamente diferenciables de interacción social que concentran en forma diferenciada la capacidad de actuación del Estado y de los actores sociales en torno a las modalidades de las nuevas condiciones económicas.

Como ya se ha indicado, las políticas sociales nacieron y se desarrollaron en el marco de las sociedades capitalistas, asumiendo características diferentes según los países. Fueron el mecanismo del Estado de Bienestar aunque guardaron su identidad como Régimen (de Bienestar), cuyos rasgos fueron la desmercantilización, el empleo y la diferenciación social ${ }^{3}$.

Al respecto, Mulvale (2001: 33) comenta que "Mediante la función de instituciones públicas específicas, los regímenes del Estado de Bienestar perseguían la promoción de un proceso de distribución de ingreso y/o niveles de consumo. Este proceso está mediatizado por condi- 
cionantes de la dinámica misma de la sociedad capitalista, la cual está atravesada por intereses de clases; por consiguiente este proceso de redistribución responde contradictoriamente a la legitimación de un orden jerárquico y a los intereses de los trabajadores, quienes iban conquistando derechos legítimos de la ciudadanía social".

Tradicionalmente, estas políticas sociales se caracterizaron por destinar un alto costo presupuestario para su implementación, con resultados poco eficaces para resolver los problemas derivados de la pobreza: aumento de la fragmentación social, desafiliación institucional, mayor sometimiento de marginalidad y autoexclusión, violencia múltiple, etc. Eran consideradas como acciones que se derivaban de las políticas de Estado, que tenían como finalidad disminuir las desigualdades sociales. Expresado de otro modo, las políticas sociales tuvieron la intención de corregir las consecuencias negativas generadas por la acumulación del capital. En este sentido, tenían una finalidad redistributiva y equitativa frente a la necesidad, con una perspectiva compensatoria y correctiva (Marshall 1949: 79).

Siguiendo esta línea argumentativa, Mulvale (2001) identifica diversas concepciones que enfocan la política social como una política de Estado. En opinión de este autor, presentan sesgos significativos compartidos por otros autores que han revisado la evolución del concepto, tanto en su sesgo reproductivista (incremento del bienestar social) como redistributivista (redistribución del ingreso). Las políticas sociales son también interpretadas según las funciones y metas que estarían llamadas a cumplir: funciones económicas como incidir en la reproducción de la fuerza de trabajo; políticas: prevenir y/o controlar la conflictividad social; ideológicas con objetivos declarados y no declarados (Coffey 2004).

Hay autores que se inscriben en la perspectiva ampliada de la política social, insistiendo que debe ser parte de una política de desarrollo social dirigida al conjunto de la sociedad y no sólo a los sectores más vulnerables. Se destacan los riesgos de reemplazar la primera por la segunda, y, peor aún, los riesgos de sustituir una política por una simple estrategia de mitigación de pobreza, como ha venido ocurriendo desde 1989 en varios países de América Latina (Minujin y Bustelo 1999). Así, Bustelo (2000) plantea que cualquier alternativa de una política social debe ser considerada dentro de un proceso histórico de desarrollo de dicha política, el que debe ser resumido de una manera muy simple, una marcha conceptual desde la compasión hasta los derechos.

Además, debe existir una relación entre el sistema social y las políticas sociales como principio de organización, cuya función sea la regulación de la crisis de reproducción social, y cuya finalidad sea mantener las condiciones de la producción y el desarrollo social. 


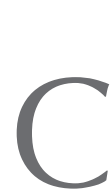

omo se estableció en la sección anterior, la intención de la política neoliberal ha sido reducir las responsabilidades y acciones del Estado, depositando en la sociedad civil la responsabilidad por el desenvolvimiento social. Las consecuencias que se han producido son la diversificación de las políticas públicas en acciones puntuales y focalizadas, respondiendo a las consecuencias de los procesos de reconversión y su influencia en el mercado de trabajo.

En otras palabras, los cambios en las políticas económicas han traído aparejados alcances importantes respecto a la población más empobrecida, agudizando de esta manera los problemas sociales. Al respecto, se plantea que los principales puntos de vista serían:

1. Entender la política social en tanto política pública, donde "política" sería un espacio de decisión sociopolítica que involucra un tipo determinado de racionalidad, a través de la cual se asignan valores a la población o a grupos de ella.

2. La política pública se entiende como el proceso mediante el cual el Estado diseña y ejecuta una política dirigida a un sector mayoritario de la población; esa política puede involucrar no sólo acciones, sino también omisiones respecto de asuntos de interés para determinados actores.
3. La política social como política pública es un término que tiene límites muy vagos y contenidos muy amplios porque está complejamente relacionado con todos los aspectos de la vida social.

4. Como política pública, la especificidad de la política social depende de los objetivos y significados de su acción.

La política social entendida como política pública se gesta con mayor intensidad en el entramado de relaciones que influyen sobre la agenda en la toma de decisiones respecto de la "cuestión social", lo evidente y lo oculto de ese proceso. Esto permite entender la política social como un proceso en el que los distintos actores que la protagonizan desarrollan prácticas cuyos contenidos obedecen a una pluralidad tanto de valores como de fines. En este sentido, se refuerza la idea que las políticas sociales precisan de la participación efectiva de los sectores populares, ya sea de una manera directa o indirectamente, a través de intermediaciones capaces de expresar sus demandas y necesidad (Coffey 2004: 48-50).

Al interior de las políticas públicas, las políticas sociales han constituido un ámbito receptor de todas las transformaciones en sectores como salud, educación, vivienda, asistencia social y demás. Como lo define Hintze: "(en América Latina) la creciente preocupación por la temática de las políticas sociales se 
relaciona con la secuela de pobreza y exclusión social, resultado de la crisis socioeconómica y del ajuste estructural que ha marcado la última década y media en la región, que ha generado aún fuertes niveles de desigualdad social. Por su parte, las políticas sociales hasta ahora implementadas han mostrado una escasa capacidad para resolver estos problemas" (2000: 15).

Por su parte, Amartya Sen (1995) plantea que la política social es concepto subjetivo y no significa un acceso a bienes, sino a una disposición de libertad o capacidad de elección. La calidad de vida, en ese sentido, se mide en capacidades de funcionamiento antes que la disposición de bienes y recursos. Este planteamiento no asocia bienestar con el consumo, puesto que no hay que desconocer que hay individuos que disfrutan del bienestar con su consumo mínimo. Debemos entender entonces que estas políticas no son más que la expresión fragmentada de las relaciones de clase $y$, en sentido ideológico, manifiestan los rasgos básicos del modelo de acumulación.

Otros autores (Howell y Pearce: 2001) desarrollan esta idea criticando las limitaciones del modelo dominante de las décadas de los ochenta y noventa observadas en los países de la periferia, incluyendo América Latina. Este punto de vista plantea la necesidad y urgencia de su revisión integral que genere un espacio para la reapertura del debate internacional sobre el de- sarrollo y la revisión misma del concepto. Esta perspectiva focaliza la cuestión en el papel que juega la inequidad, tradicionalmente relegado de la agenda de la discusión, propiciando un giro de las políticas públicas, especialmente las políticas sociales hacia los ciudadanos, impulsando una política de desarrollo económico de "abajo hacia arriba". Este planteamiento pone énfasis en las inversiones que acumule el "capital humano" y en la creación de condiciones favorables para el fortalecimiento del "capital social", donde la generación de un clima de confianza sería vital para el fomento de un cambio de actitudes de los destinatarios de las políticas sociales estatales, y en general para una participación más intensa y efectiva de la población en organizaciones de base de la sociedad civil.

Ha sido evidente que la inoperancia política y la ineficiencia administrativa, característica de la mayor parte de gobiernos en los últimos años, horadaron el sistema social, produciendo la pérdida de referentes normativos en los distintos grupos sociales. Esta se ha hecho presente de manera más contundente en aquellos que, por su situación, carecen de posibilidades de generar expectativas que produzcan movilidad social. En consecuencia, la proliferación de subculturas, que se perpetúan a través de diversos mecanismos de reproducción intergeneracional de pobreza y exclusión, van conformando un tipo de sociedad distinta de una política social 
de integración y de una ciudadanía social deformada.

Por esta razón, es importante destacar que una de las acciones de cambio se sustenta en la necesidad de regular el proceso de descentralización con arreglos políticos, que permita aumentar la capacidad de las fuerzas sociales y políticas locales. De esta manera, la asistencia podría legitimar las demandas sociales de los grupos subalternos y ampliar el protagonismo como sujetos. No como sucede actualmente respecto de la distribución limitada de los recursos del Estado, vinculada más a objetivos electoralistas que reproducen una lógica de sumisión y teniendo en cuenta que las medidas Ilevadas a cabo hasta ahora producen una respuesta fragmentada a la situación.

\section{IV}

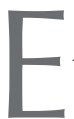
términos específicos, la focalización implica una selectividad de los objetos de las políticas sociales. Surge como alternativa ante la reducción del gasto público por parte del Estado ante el ajuste estructural exigido por los organismos internacionales. Este trajo aparejado un costo social con un efecto constante del aumento de la pobreza. El nuevo escenario redundó en estrategias diversas para enfrentar la indigencia y la focalización se convirtió en una de esas acciones.

La política de focalización se emplea como respuesta cuando existen recursos limitados por un plazo considerado de tiempo, incluyendo provisión de servicios y relativamente buenas condiciones de acceso. Aunque existe otro punto de vista, el cual considera que el sector público debe concentrarse en acciones a los más necesitados, independientemente de los recursos disponibles. Así, Howell y Pearce plantean que "las políticas focalizadas vienen a compensar la falla de un sistema que se muestra incapaz de articular a los diferentes grupos poblaciones desde su mecanismos globales de regulación" (2001: 53).

Por su parte, Alvarez aclara que "la selectividad y focalización se plantean como una tendencia a lograr una mayor equidad del gasto, y estan definidas por la concentración del gasto social en rubros y categorías de mayor impacto distributivo, como la educación básica, el reentrenamiento de la fuerza de trabajo y el saneamiento y la salud básica. La focalización del gasto estaría dirigida a los grupos de mayores carencias y a aquellos cuya atención es decisiva para el desarrollo de potencialidades futuras, como madres embarazadas, lactantes, niños y jóvenes" (2000: 141).

La focalización como estrategia también introduce una modalidad asistencial, fundada en valores y principios liberales que supone que la reproducción social será fruto del mercado como asignador de bienes. Esta protección social sólo se destina a quienes han fracasado en el mercado, negando, invirtiendo lo que constituye las condiciones 
propias de ciudadanía entendida como principio igualitario.

Algunos comentaristas (Grassi et al.) indican que "la estrategia de focalización es el correlato de la individualización de la fuerza de trabajo y de la posibilidad de la exclusión de una parte de ella del mercado de trabajo; es decir, de la forma legítima de acceder a los recursos. Del mismo modo que la estrategia del desarrollo de la comunidad fue una estrategia coherente con el contexto desarrollista" (1994: 121-124). Entonces, la focalización como estrategia surge en un contexto de escasez de los recursos disponibles e implica una distribución geográfica del gasto, que redunda en un mejor financiamiento de las necesidades.

Los grupos destinatarios se agrupan según criterios de vulnerabilidad o criticidad y se califican por grupos etáreos o sociales, aunque es cierto que estas necesidades no sólo incluyen a la población objetivo de los programas, sino además implican un acaparamiento político. Por otra parte, la focalización y la determinación de población objetivo de la asistencia no son novedosas. Los recursos fueron escasos con relación a las necesidades a cubrir, la "selección de la población" para programas de asistencia o indigencia asistida, según Castel (1997), ligada a situaciones de orden individual-privado (invalidez, abandono, viudez, madre-soltera, etc.). La diferencia es que se ha extendido esta estrategia a campos constituidos como universales. En la actualidad, los necesitados de asistencia por parte del Estado no son una minoría, sino altas proporciones de población, por lo cual la selección de beneficiarios se delimita técnicamente.

Como metodología, la focalización se aplica en casos que requieran complementar y corregir el déficit de políticas sociales o públicas, y permite lograr una mayor eficiencia en el uso de los recursos. Para esto se necesita de una previa identificación de la población, contando con una adecuada estructura de monitoreo y control de la intervención política, aunque esto no excluye el clientelismo político que siempre intercede en los programas sociales como una modalidad que remarca la situación de desigualdad de base.

\section{V}

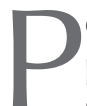

or lo desarrollado hasta aquí puede verse que las políticas sociales actuales reflejan los modelos políticos que se caracterizan por tener economías abiertas, que suponen una reforma en el ámbito político institucional y programático: focalización y medidas compensatorias. Al respecto, Portes (1999) plantea que se trata de buscar soluciones no económicas y menos costosas a los problemas sociales. Por estas razones, es factible pensar que las políticas de los programas sociales ponen en descubierto la insuficiencia de los mecanismos institucionales, repre- 
sentando, además, un dispositivo de legitimación de las actuales políticas económicas. Es importante, entonces, reconocer que las políticas son focalizadas y no integrales como antes, y están enfocadas a paliar los sufrimientos individualizados con la finalidad de apaciguar alguna parte de la estructura social. Esto tuvo como consecuencia la desaparición de las concepciones "solidaristas" que en algún momento orientaron las políticas imperantes en la década de los cincuenta en varios países de la región.

Si bien las políticas sociales se originan con la intención de frenar las demandas de la clase trabajadora, permitiendo al Estado la institucionalización y la administración de las diferencias entre sectores, en los últimos años estas políticas se centraron en los grupos excluidos, convirtiéndose en mero ámbito de manipulación y clientelismo. En el plano asistencial, generaron el recorte de algunos bienes de consumo y en el mercado de trabajo puestos de trabajo precarizados.

En este sentido, Offe (1984) vierte una opinión sobre los criterios de inclusión de beneficiarios a estos programas, planteando que son más que nada la razón burocrática para garantizar el éxito de las políticas neoliberales. Estas políticas tienen una función social expresada en servicios sociales y asistenciales diversos, a consecuencia de las limitaciones en la seguridad pública. Mulvale (2001) expone su punto de vista crítico y refiere que "esa función social enmascara y encubre las funciones esenciales que las políticas sociales desempeñan en el mundo capitalista, al presentarse frente a los individuos como mecanismos institucionales tendientes a disminuir las desigualdades sociales, retribuyendo los escasos recursos en el sentido contrario al del mercado: quienes menos tienen recibirán de las políticas sociales. Pero este sistema de solidaridad social no es otra cosa que la cáscara, la punta de un iceberg, que encubre y oculta el carozo de la cuestión; en este caso, sus funciones políticas y económicas" (Mulvale 2001: 207).

El carácter predominante de una modalidad asistencial fue reduciendo el estilo de intervención que se traduce sólo en acciones de emergencia. La metodología de la intervención opera atendiendo a un grupo de población que queda fuera del sistema y se le incorpora a programas residuales y de bajo costo en el gasto público. Sin duda, la marcada tendencia a la ausencia de responsabilidad y el desfinanciamiento que en los últimos años caracterizó al Estado producen una desprotección continua en los sectores trabajadores que se verifica en el perfil que asumen estas políticas sociales. Su función parcializada y fragmentada termina atendiendo problemáticas específicas y reproduciendo las desigualdades sociales.

Los efectos ocasionados por los programas de ajuste implementados por los organismos internacionales que incidieron en el aumento de 
la pobreza han conducido a la implantación de medidas reparadoras para "aliviar la pobreza", con programas estatales apoyados financieramente por esos mismos organismos internacionales, según Laurell, "que tienen como objetivo declarado garantizar niveles mínimos de alimentación, salud y educación para la población pobre (...) Sin embargo, con la simple confrontación entre los datos de la magnitud de la pobreza y de los recursos dedicados a estos programas, se pone de manifiesto que están lejos de lograr sus objetivos (...) Estos hechos permiten afirmar que los programas contra la pobreza tienen una agenda oculta en América Latina: el de asegurar una clientela política en sustitución del apoyo popular basado en un pacto social amplio, imposible de establecer en el marco de las políticas neoliberales" (Laurell 2000: 223).

El resultado actual que embarga a toda América Latina es claramente expresado por Laurell cuando resume: "la situación precaria del empleo y el bajo nivel del salario o de otras formas de ingreso -que son el mecanismo regular para satisfacer las necesidades sociales- se traducen en graves deficiencias en las condiciones básicas de vida: alimentación, vivienda, servicios de saneamiento, básico, educación y salud. De esta manera, grandes grupos de la población no tienen cubiertas sus necesidades sociales básicas y, mucho menos, cuentan con protección contra las contingencias sociales" (Laurell 2000: 223).

Por lo expuesto, se puede comprender que los programas sociales se convierten en un mecanismo de control social a través de los cuales los grupos y actores con mayor poder ejercen una fuerte influencia para legitimar las perspectivas e ideologías en las zonas de pobreza. El control se manifiesta en las consecuencias que arrastran estos enfoques programáticos, que producen inhibición de la acción colectiva y reducen las prácticas a una continuidad de las medidas asistencialistas y perpetuando clientes en los proyectos sociales. Habría que evaluar los efectos que ocasiona este Estado reducido respecto de la responsabilidad sobre los sectores vulnerables, que opera sólo a favor del aumento del capital.

\section{VI}

- n condiciones de crisis, el sujeto colectivo que definía la integración a la sociedad a través de la protección dada por la legislación "sujeto de derechos sociales" se desagrega considerando a los "individuos", ya sea para su integración o exclusión y se define sólo en el mercado como única instancia legítima, abandonando derechos percibidos como universales. Las políticas asistenciales funcionan dentro del sistema social como una institución de apoyo que legitima el sistema. En otras palabras, son el resultado de las relaciones entre la sociedad y el Estado y llevan im- 
plícitos mecanismos que permiten manejar esas relaciones.

Su finalidad manifiesta es regular las condiciones de producción social, neutralizando los conflictos sociales e integrando los grupos sociales vulnerables y los tradicionalmente excluidos. Sin embargo, terminan produciendo lo que se dado en llamar la "ciudadanía invertida". Estos grupos son identificados como grupos subalternos de una sociedad formada por grupos de desamparados que dependen de esas acciones que determinan estas políticas. Políticas que siempre encubren relaciones de dominación más profundas, por estar ligadas a parámetros no sólo ideológicos sino también de gestión de recursos públicos. En el contexto de crisis, en cambio, el sujeto colectivo que definía integración a la sociedad, a través de la protección dada por la legislación sujeto de derechos sociales, se desagrega considerando a los individuos, ya sea por su integración o su exclusión. Se define sólo en el mercado como única instancia legítima, marginando derechos percibidos como universales.

Los derechos sociales, por su parte, presuponen igualdad y son capaces de estructurar las relaciones sociales derivadas del capitalismo. Esto no deja de lado que la inclusión al sistema produce a través del empleo, por esta razón Beccaria (2002) la incluye como variable en su análisis.

Desde otra perspectiva, puede observarse que, como consecuen- cia de la continua gravedad social y económica, la estrategia de asistencia forma parte de una de las modalidades más perpetuadas por el Estado, el cual de esta manera demarca la política social. Estas estrategias pueden identificarse como neoasistenciales, porque siguen manteniendo la mirada clásica hacia los destinatarios como pobres pusilánimes.

Estas acciones de ayuda perpetúan la matriz conservadora porque siguen formando sujetos dependientes de las prácticas y determinaciones del Estado, eliminándoseles como sujetos de derechos y reduciéndoles a objetos de las políticas compensatorias. En muchos países, las reformas que se vienen desarrollando en razón del derecho a la salud se amplían a un concepto más abarcador como es el derecho a la ciudadanía. Este concepto integra beneficios que posibilitan las políticas sociales, pero comprendiendo lo que corresponde a la conciencia ciudadana.

El asistencialismo, por su parte, invierte el derecho ciudadano al constituir un clientelismo que intercambia favores asistenciales basados en la idea de la caridad. Como lo indica Álvarez, "las políticas asistenciales implican la construcción del problema social, por lo cual el campo de los discursos acerca de la política social se caracteriza por la competencia y el conflicto entre los distintos paradigmas o principios productores de representaciones que, en forma mediada, expresan 
distintos intereses sociales" (2000: 141).

Enfocado de esta manera, el campo de la asistencia social termina produciendo una burocratización de las políticas públicas y un marcado perfil fragmentado caracterizado por la desarticulación de las acciones, la falta de competitividad y la inequidad en la distribución de recursos. Si desde el Estado no se imparten iniciativas para potenciar este cambio, es lógico suponer que los efectos sobre los beneficiarios serán más programas compensatorios. Los recursos asignados fijan límites a la oferta de servicios y reformulan las prácticas que el mismo Estado, en un contexto capitalista, ha mantenido históricamente, como son las acciones específicas para grupos sin condiciones de reproducir su propia subsistencia y estrategias compensatorias que hacen más evidente la desigualdad estructural que sufren aquellos atrapados en la pobreza. Sin duda, esta cuestión permite mostrar la permanencia del significado ideológico que siempre ha marcado a la asistencia como es el control social.

En resumen: mirar la política social no sólo para el ciudadano sino por y desde el ciudadano, incluyendo la perspectiva cotidiana y su potencialidad para lo cual es necesario indagar y poner de manifiesto su actitud ante la pobreza y ante la intervención oficial del Estado. Una intervención que no deja de producir respuestas fragmentadas ante los objetivos propuestos en sus políticas. Porque no hay que desconocer que el concepto igualitario de ciudadanía también ha servido para encubrir la exclusión de importantes sectores sociales. De esta manera, las políticas focalizadas de combate a la exclusión han sido divulgadas como aportes a las políticas universalistas, generando un falso antagonismo que recientemente empiezan a ser disuelto a pesar de las políticas selectivas.

Las luchas por la inclusión en la condición de ciudadanía en grupos vulnerables van dejándose de lado como objetivo por parte del Estado, en parte por fomentarlos en su agrupación y en parte por su incapacidad de solucionarlas. Si las políticas tienen como función brindar cierta seguridad a la gente, reduciendo la incertidumbre que afecta a estas personas, la implementación de políticas ineficientes ha aumentado estos factores que llevan a la incertidumbre, pero, peor aún, ha reducido las estrategias de supervivencia de la población "beneficiaria", que ha quedado atrapada en una estructura altamente dependiente del Estado.

A título de conclusión, se podría afirmar que el absolutismo que caracteriza al modelo neoliberal termina por generar consecuencias detrimentes para los grupos populares y marginados. Mientras tanto, encontrar un modelo alternativo que sea capaz de garantizar la transformación democrática, el desarrollo y la equidad social, todavía es una construcción muy difícil en el con- 
texto de la exclusión generalizada como el de la América Latina. Pero, es también una posibilidad que puede ser construida a través de la participación efectiva de los secto-

Notas

1 También llamadas políticas de "reducción de la pobreza", "superación de la pobreza", "combate a la pobreza”, "mitigación de pobreza”, entre otras. La utilización de cada una de estas denominaciones no es neutra, puesto que encierra una visión de pobreza y una forma de intervenirla. Además, los distintos actores o instituciones se caracterizan por asumir una de ellas. Sin embargo, en el presente trabajo se habla de "políticas de alivio a la pobreza" (o como en algunos casos se les denomina eufemísticamente "Redes Solidarias"), pues quedan reducidas a medidas sociales que buscan ayudar a los pobres de una manera temporal y neutralizar los costos sociales y políticos del modelo neoliberal, la

\section{REFERENCIAS}

Álvarez, S. (2000) "Políticas de desarrollo social, transformaciones y paradojas", en Hintze, S. (Comp.) Estado y Sociedad. Las políticas SOciales en los umbrales del siglo XXI. Buenos Aires: Eudeba. 141-160.

Beccaria, L. (2002) Conferencia sobre Desempleo, pobreza y exclusión social. Disponible en www. cambiocultural.com.ar

Bustelo, E. (2000) "Políticas sociales: Aproximación desde la Po- res democráticos-nacionales comprometidos en impulsar la reforma social y en la construcción de un nuevo estilo de desarrollo.

naturaleza y el alcance de las medidas se orientan hacia el alivio de la pobreza, mas no a su superación o eliminación. En este sentido, puede decirse que quedan supeditadas a las exigencias del modelo económico dominante.

2. Offe discute los puntos de referencia en relación al carácter cada vez menos objetivo de la fuerza determinante de realidades como el trabajo, la producción, el mercado, en su relación con la constitución social y el desarrollo de la sociedad en su conjunto.

3 A diferencia del Estado de Bienestar, el Régimen de Bienestar se concentra en las vinculaciones legales y organizativas entre la economía y el Estado (Esping-Andersen 1990). lítica", en Hintze, S. (comp.) Estado y Sociedad. Las políticas sociales en los umbrales del siglo XXI. Buenos Aires: Eudeba. 41-48.

Castel, R. (1997) La metamorfosis de la cuestión social. Una crónica del salariado. Paidós: Argentina.

Coffey, A. (2004) Reconceptualizing social policy. Sociological perspectives on contemporary social policy. Open University Press: London y New York. 
Esping-Andersen, G. (1990) The three worlds of welfare capitalism. Princeton: Princeton University Press.

Grassi, E. Hintze, S. y Neufeld, M. (1994) Políticas Sociales: crisis y ajuste estructural. Buenos Aires: Espacio Editorial.

Hintze, S. (comp.) Estado y Sociedad. Las políticas sociales en los umbrales del siglo XXI. Buenos Aires: Eudeba.

Howell, J. y Pearce, J. (2001) Civil Society and Development. Boulder, Colorado: Lynne Rienner Publisher.

Jessop, B. (2002) "Liberalism, Neoliberalism, and Urban Governance: A State-Theoretical Perspective" en Antipode, 34/3. 452-472.

Laurell, A. C. (2000) "Avanzar al pasado: la política social del neoliberalismo", en Borgianni, E. y Montaño, C. La Política Social Hoy. São Paulo: Cortez Editora. 223-260.

Marshall, T. H. (1949) Citizenship and social class. Reimpreso en Held, D. et al. (1983) Studies and societies. Londres: Open University.

Minujin, A., Bustelo, E. y Tenti, E. (1993) Cuesta abajo. Documento de discusión. Universidad de La Serena. Chile.

Mulvale, J. P. (2001) Reimagining social welfare: beyond the Keynesian welfare state. Toronto: Garamond.

Offe, C. (1984) Contradictions of the Welfare State. Cambridge, Mass.: The MIT Press.

Portes, A. (1999) "Capital social: sus orígenes y aplicaciones en la sociología moderna", en Portes, A. De igual a igual: El desarrollo del Estado ante los problemas sociales. Buenos Aires: FLACSO. 65-78.

Sen, A. (1995) The Political Spending and the Poor. Theory and Evidence. Baltimore; Johns Hopkins University Press.

Stiglitz, J. (2002) Globalization and its Discontents. New York: Norton. 